\title{
Surgical management of benign prostatic obstruction: 20-year population-level trends
}

Joseph R. LaBossiere'; Christopher J.D. Wallis ${ }^{2}$; Sender Herschorn²; Lesley Carr²; Refik Saskin ${ }^{3}$; Robert Nam ${ }^{2}$

${ }^{1}$ Division of Urology, Department of Surgery, Northern Alberta Urology Institute, University of Alberta, AB, Canada; ${ }^{2}$ Division of Urology, Department of Surgery, Sunnybrook Health Sciences Centre, University of Toronto, ON, Canada; ${ }^{3}$ Institute of Health Policy, Management \& Evaluation, University of Toronto, ON, Canada

Cite as: Can Urol Assoc J 2020 March 23; Epub ahead of print. http://dx.doi.org/10.5489/cuaj.6224

Published online March 23, 2020

$* * *$

\section{Abstract}

Introduction: Benign prostatic obstruction (BPO) due to histologic benign prostatic hyperplasia is highly prevalent among older men. Despite widespread use of medical therapy, surgical treatment remains a mainstay in the management of BPO. We sought to characterize trends in the surgical management of BPO in Ontario, Canada.

Methods: We performed an interrupted time-series analysis using segmented regression among men aged 18 years and older undergoing surgical treatment for BPO between January 1, 1994 and December 31, 2014 in Ontario, Canada. The passage of time was considered the primary exposure. The primary outcome was the proportion of all BPO surgeries performed using each of the following modalities: transurethral resection of the prostate (TURP), endoscopic laser prostatectomy, open/laparoscopic prostatectomy, and others.

Results: We identified 136459 men who underwent BPO surgery between 1994 and 2014. The annual age-adjusted rate of BPO surgery declined significantly over time (24 to 10 per 10000 population in 1994 and 2014, respectively). From 1994 to 2001, there were no significant changes in the distribution of BPO surgical modalities with TURP, the most common throughout (97.2\% and 97\% in 1994 and 2001, respectively). From 2002 to 2014, there was a significant decline in the use of TURP $(92.1 \%$ to $76.9 \% ; \mathrm{p}=0.027)$ with a corresponding increase in the use of endoscopic laser prostatectomy $(3.5 \%$ to $21.9 \%$; $=0.0008)$.

Conclusions: This study demonstrates a shift in the management of BPO, with increasing use of endoscopic laser prostatectomy, beginning in 2002. However, TURP remains the most common treatment modality. 


\section{Introduction}

Benign prostatic obstruction (BPO) due to histologic benign prostatic hyperplasia contributes to significant lower urinary tract symptoms among aging men. By the seventh decade of life, such voiding symptoms affect nearly $75 \%$ of men. ${ }^{1,2}$ Historically, surgical treatment, either transurethral resection of the prostate (TURP) or simple open prostatectomy, was the treatment of choice. Since the early 1990s, medical therapy for BPO has been indicated as first line treatment for men with moderate to severe symptoms. ${ }^{3}{ }^{4}$ However, surgical treatment remains the standard of care among patients for whom medical therapy is ineffective, who are unwilling to try medical therapy and those with complications due to BPO. ${ }^{3}$ While TURP remains the gold standard therapy, ${ }^{3}$ recent data have shown that endoscopic laser prostatectomy (photovaporization and enucleation) may confer similar outcomes with lower rates of complications $^{5,6}$ and overall costs. ${ }^{7}$

We sought to assess trends in the surgical management of benign prostatic obstruction (BPO) utilizing population-level data from the Province of Ontario, a jurisdiction with a single payer health care system capturing a population in excess of 13 million.

\section{Methods}

We conducted a retrospective cohort study of men undergoing surgical management of BPO in the province of Ontario between January 1, 1994 and December 31, 2014. In Ontario, medical care is reimbursed by a single, government-funded health insurance system (Ontario Health Insurance Plan, OHIP) which finances both inpatient and outpatient care. We used Canadian Classification of Health Intervention (CCI) codes to identify patients in the Canadian Institute of Health Information (CIHI) Discharge Abstract Database and National Ambulatory Care Reporting System databases, both of which are validated data sources. ${ }^{8}$ Using CCI codes, we categorized patients as having received TURP, endoscopic laser prostatectomy, open/laparoscopic prostatectomy or other BPO procedures (including microwave, radiofrequency or ultrasound endoscopic destruction of the prostate). We excluded patients coded as female, those under the age of 18 at the time of surgery and those with a history of prostate cancer prior to surgery. We considered only the first BPO surgery during the time interval.

This study was approved by the Sunnybrook Health Sciences Centre Research Ethics

\section{Board.}

\section{Outcomes}

We first examined the two- and five-year cumulative incidence of BPO surgery in men, stratified by age categories, to examine for overall trends in the rates of these procedures.

Second, as our primary outcome, we examined trends in the use of particularly surgical approaches, namely TURP, endoscopic laser prostatectomy, open/laparoscopic prostatectomy and other BPO procedures, over time. We measured these as a proportion of all BPO treatments. 
Finally, we examined trends in the patient characteristics at the time of BPO surgery over time. We assessed comorbidity using the Johns Hopkins resource utilization band (RUB) score and operationalized this as a categorical variable. Age was operationalized both by calculating the mean age and by categorizing it (age $<50$ years, $50-60$ years, $60-70$ years, $70-80$ years and $>80$ years).

\section{Statistical analysis}

First, we calculated the two- and five-year cumulative incidence of requiring a BPO surgical intervention, stratified by age group $(<50,50-59,60-69,70-79,>80$ years old $)$. We examined the entire population of Ontario and calculated the cumulative incidence of intervention per 1000 population for men who were in each age group as of 1995, as of 2000, as of 2005 and as of 2010 using the Kaplan-Meier method in order to identify changes over time. We quantified trends in the cumulative incidence of BPO surgery over time using the Cochran-Armitage test for trend.

For our primary outcome, we performed an interrupted time series analysis using segmented regression (also known as piecewise regression or 'broken-line' regression) to assess for significant trends in the proportion of BPO procedures performed using each modality over time. We controlled for the first and the second order autoregressive effects. The higher order effects were not found to be significant. As there was a transition from the Canadian Classification of Diagnostic, Therapeutic and Surgical Procedures (CCP) coding to Canadian Classification of Health Interventions (CCI) coding in 2002 and this date corresponded with the introduction of laser prostatectomy in the region, we analysed trends in the utilization of each procedure before and after 2002.

In order to analyse the trends in patient comorbidity over time, we used ordinal logistic regression with possible outcomes of RUB scores $0,1,2,3,4$ and 5. Results were expressed as the odds ratio (OR) and $95 \%$ confidence interval (CI) associated with each year. To examine trends in patient age over time, we first used linear regression to examine changes in the mean age over time. We then used ordinal logistic regression to examine changes in the distribution across a categorical age variable (age $<50$ years, 50-60 years, 60-70 years, 70-80 years and $>80$ years).

All statistical analyses were performed using SAS 9.3 (SAS Institute Inc., Cary, NC, USA). Statistical significance was set at $p<0.05$.

\section{Results}

We identified a total of 136,459 men who underwent surgery for BPO between 1994 and 2014 in the Province of Ontario. The vast majority of all interventions were transurethral resection of the prostate (TURP), representing $91.5 \%(\mathrm{n}=124,859)$ of all BPO surgeries. Endoscopic laser prostatectomy was performed in $8526(6.2 \%)$ of patients and open/laparoscopic prostatectomy was performed in $2003(1.5 \%)$. Only $1071(0.8 \%)$ of patients received an "other BPO 
intervention". Most patients were aged 70 and older $(58.5 \%, \mathrm{n}=79,808)$ with a median age of 72 (Table 1$)$. Nearly all patients had moderate $(\mathrm{RUB}=3)$ to very high $(\mathrm{RUB}=5)$ comorbidity (Table $1)$.

The number of BPO surgeries performed annually per 10,000 population declined over time, both in crude numbers and after age-standardization to the 2001 Ontario population (Figure 1). Between 1994 and 2001, there was a significant decline in the age-standardized number of BPO surgeries (per 10,000 population) being performed annually (estimate $=-1.5$ per year, $\mathrm{p}<0.0001$ ). While there continued to be a significant decline after 2002 (estimate $=-0.3$, $\mathrm{p}=0.047)$, the magnitude of change decreased significantly $(\mathrm{p}<0.0001)$. After stratification by age, there was a significant decline in the number of BPO surgeries between 1994 and 2001 for patients aged 50 and over (Figure 2; Supplementary Table). For patients under the age of 50, there was no significant trend during this time period. After 2002, there was a modest decline in the number of BPO surgeries for patients in the 70-79 year and $\geq 80$-year age strata but no significant change for those younger than 70 (Figure 2; Supplementary Table). The two- and five-year cumulative incidence of BPO surgeries significantly decreased over time among all age groups, except men $<50$ years old (Table 2 ). The magnitude of these changes was largest among older men (age 70-79 and $>80$ years) with reductions in excess of 50\% (Table 2).

\section{Primary outcome}

There were no statistically significant changes in the use of BPO interventions from 1994 (cohort inception) to 2001 (Table 3). TURP was the most common treatment modality throughout this period with utilization of $97.2 \%$ in 1994 and $97.0 \%$ in 2001 (trend p=0.67). From 2001 to 2002, there was a statistically significant increase in the use of open/laparoscopic prostatectomy $(p=0.0008)$ which may be attributable to changes in the coding schema; no such changes were observed for TURP $(\mathrm{p}=0.32)$, endoscopic laser prostatectomy $(\mathrm{p}=0.89)$, or other BPO treatments $(\mathrm{p}=0.58)$. From 2002 to 2014 , there were significant changes in the two most common treatment modalities (Figure 3). There was a statistically significant decline in the use of TURP from $92.1 \%$ in 2002 to $76.9 \%$ in 2014 ( $\mathrm{p}=0.027$ ). Correspondingly, there was an increased use of endoscopic laser prostatectomy after 2002 (3.5\% to $21.9 \%$; $=0.0008)$. The use of both open/laparoscopic prostatectomy and other BPO treatments declined from 2002 to 2014, though this was not statistically significant (Table 3).

\section{Secondary outcomes}

Among the whole study cohort, we observed a small but statistically significant trend towards higher comorbidity among patients undergoing BPO surgery over time (OR 1.005, 95\% CI $1.003-1.007 ; \mathrm{p}<0.0001)$. When we examined each intervention separately, there was a statistically significant trend for patients receiving TURP (OR 1.006, 95\% CI 1.004-1.007; $\mathrm{p}<0.0001$ ) and open/laparoscopic prostatectomy (OR 1.036, 95\% CI 1.02-1.05; $\mathrm{p}<0.0001$ ) to 
have higher RUB scores over time, however, this was not significant among patients undergoing endoscopic laser prostatectomy $(p=0.39)$ or other BPO interventions $(p=0.43)$.

Among the whole study cohort, there was a small but statistically significant shift in the age distribution, towards an older age at the time of surgery (OR 1.003, 95\% CI 1.001-1.004; $\mathrm{p}=0.0004)$. When we examined each intervention separately, there was a statistically significant trend for more patients receiving endoscopic laser prostatectomy (OR 1.016, 95\% CI 1.0041.028; $\mathrm{p}=0.0087$ ) and TURP (OR 1.003, 95\% CI 1.002-1.005; $\mathrm{p}=0.0002$ ) to be in the older strata over time; however, there was no trend observed for patients undergoing open/laparoscopic prostatectomy $(\mathrm{p}=0.81)$ or other BPO procedures $(\mathrm{p}=0.30)$.

When we examined the mean age at the time of surgery, there was a small but statistically significant increase over time among the whole study cohort ( 0.01 years of age per year; $p=0.0014$ ). When we examined each intervention separately, there was a significant trend with the mean age increasing over time among patients treated with endoscopic laser prostatectomy ( 0.11 years of age per year; $p=0.0005)$ or TURP $(0.01$ years of age per year; $\mathrm{p}=0.0022$ ) but this was not significant among those undergoing open/laparoscopic prostatectomy $(p=0.16)$ or other BPO procedures $(p=0.56)$.

\section{Discussion}

Using administrative data, this study characterizes trends in the surgical management of BPO surgery within a single-payer, government funded health care system in Ontario, Canada. A total of 136,459 men with BPO were surgically managed between January 1, 1994 and December 31, 2014. Over the study period, transurethral resection of the prostate gland comprised the majority of interventions $(91.5 \%)$ followed by endoscopic laser prostatectomy $(6.2 \%)$, open/laparoscopic prostatectomy $(1.5 \%)$ and other BPO procedures $(0.8 \%)$. The total number of annual BPO surgeries per 10,000 patient population significantly decreased over time in patient's over the age of 50 .

No significant change in BPO surgical management trends were observed between 19942001. However, from $2002-2014$ the number of TURP procedures significantly decreased $(92.1 \%$ to $76.9 \%)$ corresponding with a significant increase in the use of endoscopic laser prostatectomy $(3.5 \%$ to $21.9 \%)$. These findings are consistent with previously reported trends internationally, ${ }^{9-14}$ though contrast with prior work in Canada. Hueber et al. captured Canadawide trends in BPO management between 2007-2011. ${ }^{15}$ The authors observed no significant change in the utilization of TURP over the time period but did find a trend towards increased use of endoscopic laser prostatectomy.

Previous studies have identified factors that may influence the decision to use endoscopic laser prostatectomy over TURP including increased patient age, higher surgeon case volume and less patient comorbidity. ${ }^{11,16,17}$ Our study identified a significant trend towards an increase in patient comorbidity over time in the TURP cohort that is consistent with prior studies ${ }^{15,18,19}$, 
though no significant trend in patient comorbidity was identified in the endoscopic laser prostatectomy cohort. Though prior studies suggest that older patients are more likely to be treated with endoscopic laser prostatectomy compared to TURP, we found that trends in patient age at the time of surgery did not differ between the treatment groups, with a significant trend towards increased patient age at the time of surgery observed in both the TURP and endoscopic laser prostatectomy cohorts.

This study is one of the largest studies to date describing trends in the surgical management of BPO and was conducted in Ontario, Canada which provides health care services free of cost to patients utilizing a single-payer health care system. Several advantages are derived from this population-based study design. First, patient health care information is systematically recorded in provincial government databases reducing recall/information bias. Second, inclusion/exclusion criteria were minimal, as such, the derived patient population reflects the true spectrum of surgical management of BPO. In addition, up to $40 \%$ of Canada's population resides within the province of Ontario ${ }^{20}$ with $40 \%$ of all BPO surgeries occurring within the province. ${ }^{15}$ In conjunction, these factors increase the generalizability of the results. Third, all BPO surgeries in the province were captured in the study minimizing selection bias. Finally, validated coding schemas were utilized to accurately categorize surgical treatment modalities, further minimizing misclassification/information bias.

We recognize certain limitations of the study. Variables that may be driving the observed trends in the surgical management of BPO including indication for surgery are not captured in the databases. As such, although significant changes in BPO management trends were observed, we cannot comment on why this is occurring. Similarly, variables that may account for the observed increase in patient age or comorbidity were not captured in the study. We hypothesize that medical management may be delaying the age at which patients receive surgical management for BPO, with older patients tending to be more comorbid. However, owing to funding eligibility of prescription medication in Ontario, data concerning medication use is not available for patients $<65$ years of age. As the purpose of this study was to accurately characterize BPO surgical management trends, age was not restricted to men over the age of 65 to ensure generalizability of the findings. We recognize that a small number of patients in the study were under the age of $50(1.2 \%)$ in which a diagnosis of BPO is quite rare. It is possible that these patients received a BPO surgical intervention for a diagnosis other than BPO, though younger patients can present with symptomatic BPO. As we used validated coding schemas to identify patients with a diagnosis of BPO who received a BPO surgical intervention, including all age groups that can potentially present with symptomatic BPO serves to reduce selection bias in this study. Further, as there are very view patients under the age of 50 included in the study, study conclusions are unlikely to have been significantly affected by inclusion of this patient population. Final limitations include a lack of population-based data preceding the introduction of medical therapies for BPO available in Ontario and the inability to capture the effect changes 
in the surgical management of BPO have had on clinical outcomes (including treatment outcomes and complications). Further studies are planned to address these limitations.

\section{Conclusions}

Our population-based study highlights a shift in the surgical management of BPO over a 20-year period. Though TURP remains the most commonly utilized modality overall, use has significantly decreased over time (presumably due to medical therapy) while management with endoscopic laser modalities has significantly increased. Further, a shift towards patients being older and more comorbid at the time of surgery was observed over the study period. This latter finding suggests that medical therapy may simply be 'delaying' surgical intervention in some men and can aid practicing physicians in establishing appropriate treatment expectations and follow-up plans for men presenting with symptomatic BPO. 


\section{References}

1. Wei JT, Calhoun EA, Jacobsen SJ. Benign prostatic hyperplasia. In: Litwin MS, Saigal CS, eds. Urologic Diseases in America. Washington, DC: US Government Publishing Office; 2007.

2. Platz EA, Smit E, Curhan GC, Nyberg LM, Giovannucci E. Prevalence of and racial/ethnic variation in lower urinary tract symptoms and noncancer prostate surgery in U.S. men. Urology. 2002;59(6):877-883.

3. Oelke M, Bachmann A, Descazeaud A, et al. EAU guidelines on the treatment and follow-up of non-neurogenic male lower urinary tract symptoms including benign prostatic obstruction. European urology. 2013;64(1):118-140.

4. Nickel, J. C., Aaron, L., Barkin, J., Elterman, D., Nachabé, M., \& Zorn, K. C. (2018). Canadian Urological Association guideline on male lower urinary tract symptoms/benign prostatic hyperplasia (MLUTS/BPH): 2018 update. Canadian Urological Association Journal, 12(10). https://doi.org/10.5489/cuaj.5616

5. Cornu JN, Ahyai S, Bachmann A, et al. A Systematic Review and Meta-analysis of Functional Outcomes and Complications Following Transurethral Procedures for Lower Urinary Tract Symptoms Resulting from Benign Prostatic Obstruction: An Update. European urology. 2015;67(6):1066-1096.

6. Ding H, Du W, Lu ZP, Zhai ZX, Wang HZ, Wang ZP. Photoselective green-light laser vaporisation vs. TURP for BPH: meta-analysis. Asian J Androl. 2012;14(5):720-725.

7. Whelan JP, Bowen JM, Burke N, et al. A prospective trial of GreenLight PVP (HPS120) versus transurethral resection of the prostate in the treatment of lower urinary tract symptoms in Ontario, Canada. Can Urol Assoc J. 2013;7(9-10):335-341.

8. Juurlink DN, Preyra C, Croxford R, al. E. Canadian Institute for Health Information Discharge Abstract Database: A validation study. Toronto, Ontario, Canada: Institute for Clinical Evaluation Sciences; 2006.

9. Schroeck FR, Hollingsworth JM, Kaufman SR, Hollenbeck BK, Wei JT. Population based trends in the surgical treatment of benign prostatic hyperplasia. $J$ Urol. 2012;188(5):1837-1841.

10. Takamori H, Masumori N, Kamoto T. Surgical procedures for benign prostatic hyperplasia: A nationwide survey in Japan, 2014 update. Int J Urol. 2017;24(6):476-477.

11. Chughtai BI, Simma-Chiang V, Lee R, et al. Trends and Utilization of Laser Prostatectomy in Ambulatory Surgical Procedures for the Treatment of Benign Prostatic Hyperplasia in New York State (2000-2011). J Endourol. 2015;29(6):700-706.

12. Malaeb BS, Yu X, McBean AM, Elliott SP. National trends in surgical therapy for benign prostatic hyperplasia in the United States (2000-2008). Urology. 2012;79(5):1111-1116. 
13. Masumori N, Kamoto T, Seki N, Homma Y, Hyperplasia CfCGfBP. Surgical procedures for benign prostatic hyperplasia: a nationwide survey in Japan. Int J Urol. 2011;18(2):166-170.

14. Kang JY, Min GE, Son H, Kim HT, Lee HL. National-wide data on the treatment of BPH in Korea. Prostate Cancer Prostatic Dis. 2011;14(3):243-247.

15. Hueber PA, Zorn KC. Canadian trend in surgical management of benign prostatic hyperplasia and laser therapy from 2007-2008 to 2011-2012. Can Urol Assoc J. 2013;7(9-10):E582-586.

16. Lee NG, Xue H, Lerner LB. Trends and attitudes in surgical management of benign prostatic hyperplasia. Can J Urol. 2012;19(2):6170-6175.

17. Lowrance WT, Southwick A, Maschino AC, Sandhu JS. Contemporary practice patterns of endoscopic surgical management for benign prostatic hyperplasia among urologists in the United States. J Urol. 2013;189(5):1811-1816.

18. Izard J, Nickel JC. Impact of medical therapy on transurethral resection of the prostate: two decades of change. BJU Int. 2011;108(1):89-93.

19. Borth CS, Beiko DT, Nickel JC. Impact of medical therapy on transurethral resection of the prostate: a decade of change. Urology. 2001;57(6):1082-1085; discussion 1085-1086.

20. Ontarior Ministry of Finance. Fact Sheet June 2018. Obtained from website: https://www.fin.gov.on.ca/en/economy/ecupdates/factsheet.html 


\section{Figures and tables}

Fig. 1. Trends in the number of benign prostatic obstruction procedures being performed annually per 10000 population.

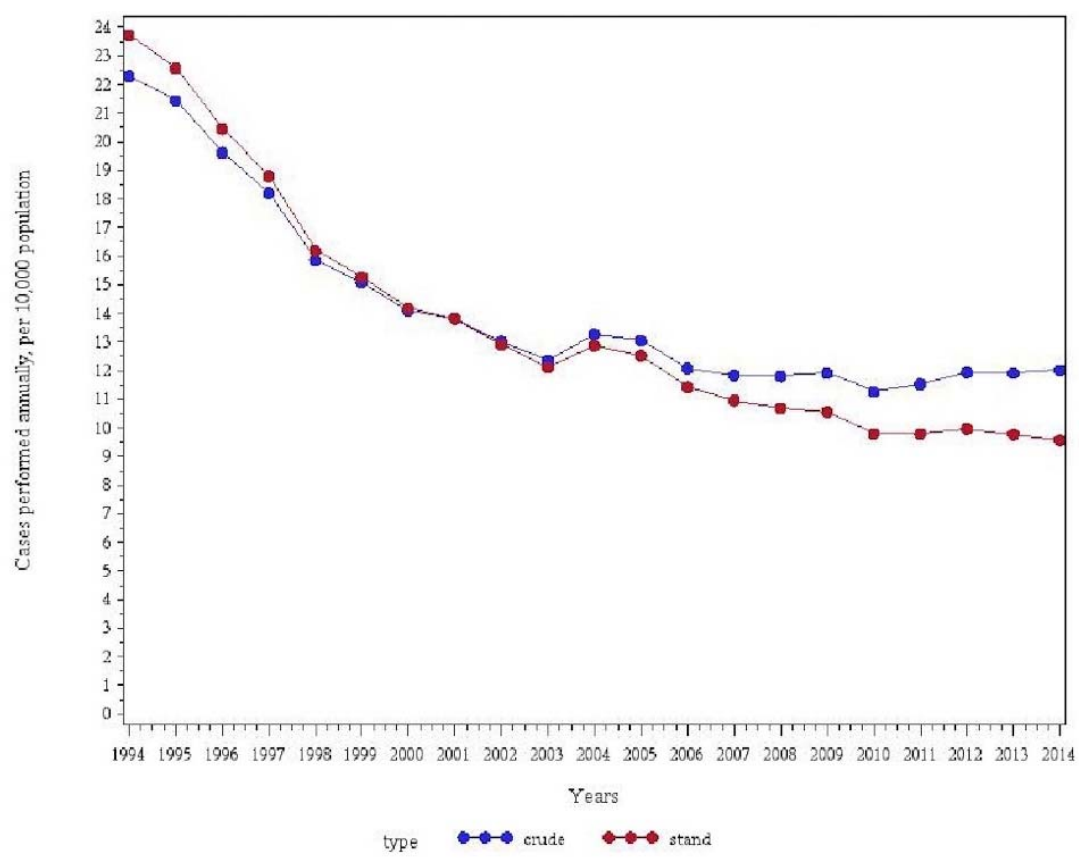

Fig. 2. Trends in the number of benign prostatic obstruction procedures being performed annually per 10000 population stratified by patient age at the time of treatment.

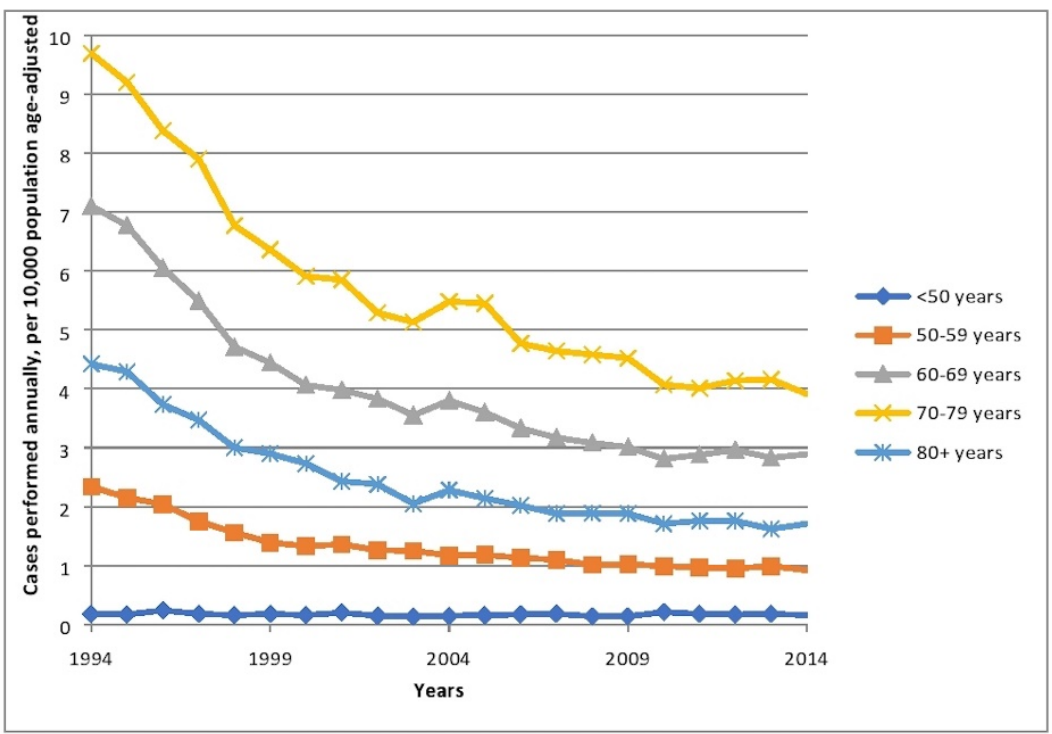


Fig. 3. Relative use of benign prostatic obstruction treatment modality from 1994-2014 in Ontario, Canada.

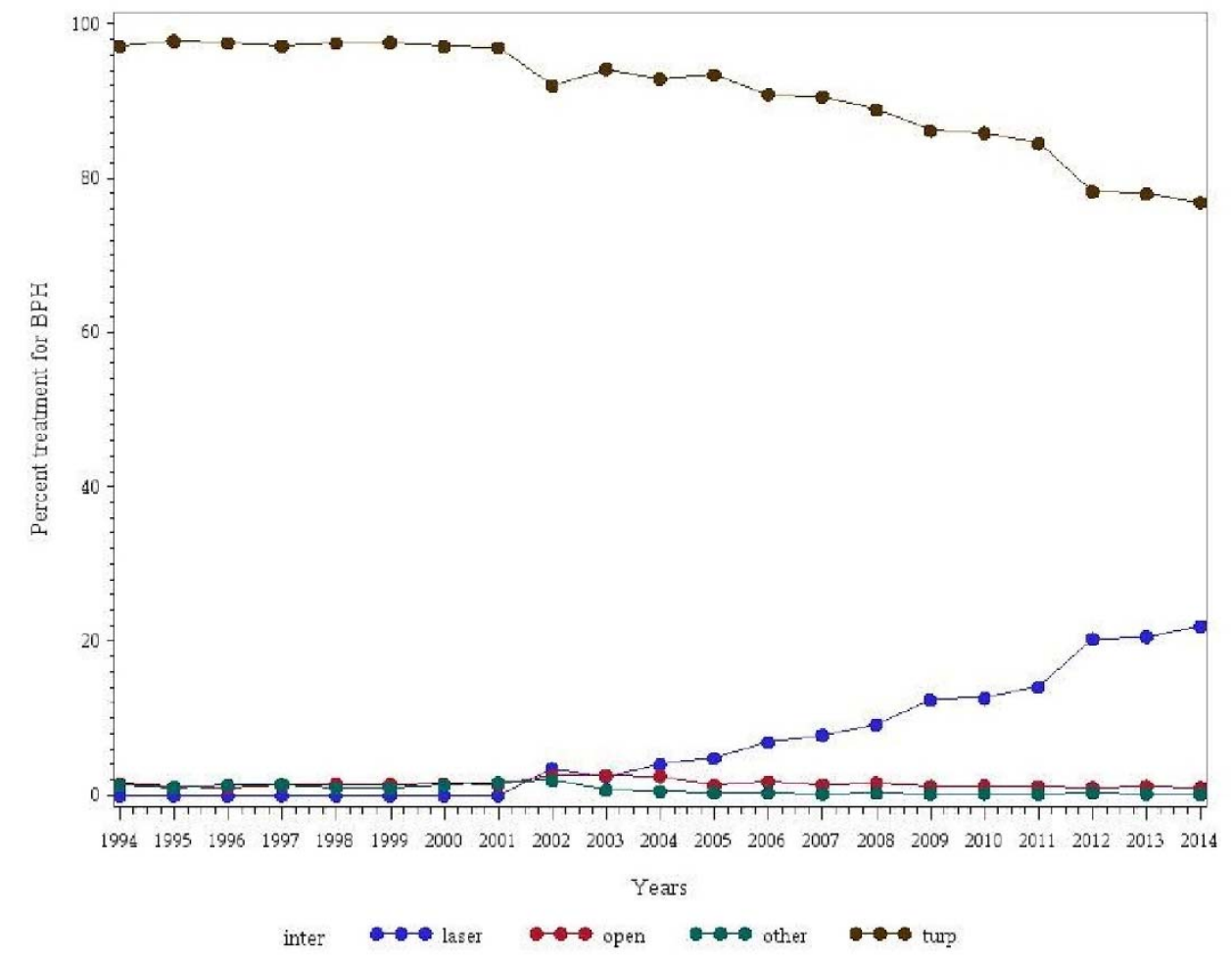




\section{Table 1. Baseline demographic characteristics of men undergoing BPH surgery in} Ontario, Canada from 1994-2014

\begin{tabular}{|l|l|}
\hline Total cohort size $(\mathrm{n})$ & 136459 \\
\hline Age (years) & $71.2(9.29)$ \\
\hline Mean $( \pm$ SD) & $72(65-78)$ \\
\hline Median (IQR) & \\
\hline Categorical, $\mathrm{n}(\%)$ & $1611(1.2)$ \\
\hline$<50$ & $12986(9.5)$ \\
\hline $50-59$ & $42054(30.8)$ \\
\hline $60-69$ & $53631(39.3)$ \\
\hline $70-79$ & $26177(19.2)$ \\
\hline$\geq 80$ & \multicolumn{2}{|l|}{} \\
\hline Income quintile, $\mathrm{n}(\%)$ & $25987(19)$ \\
\hline 1 - Lowest & $28506(20.9)$ \\
\hline 2 & $27578(20.2)$ \\
\hline 3 & $26840(19.7)$ \\
\hline 4 & $27099(19.9)$ \\
\hline 5 - Highest & $449(0.3)$ \\
\hline Missing & \multicolumn{1}{|l|}{} \\
\hline Residence, $\mathrm{n}(\%)$ & $116536(85.4)$ \\
\hline Urban & $19789(14.5)$ \\
\hline Rural & $134(0.1)$ \\
\hline Missing & \multicolumn{1}{|l|}{} \\
\hline RUB score, $\mathrm{n}(\%)$ & $32(0)$ \\
\hline 0 - Lowest & $6(0)$ \\
\hline 1 & $953(0.7)$ \\
\hline 2 & $60875(44.6)$ \\
\hline 3 & $39180(28.7)$ \\
\hline 4 & $35413(26)$ \\
\hline 5 - Highest &
\end{tabular}

$\mathrm{BPH}$ : benign prostatic hyperplasia; IQR: interquartile range; SD: standard deviation. 


\begin{tabular}{|c|c|c|c|c|c|}
\hline Age group & 1995 & 2000 & 2005 & 2010 & Trend (p) \\
\hline \multicolumn{6}{|c|}{ Two-year cumulative incidence of BPO surgery } \\
\hline$<50$ years & $0.07 \%(0.06-0.08)$ & $0.06 \%(0.05-0.07)$ & $0.06 \%(0.05-0.06)$ & $0.07 \%(0.06-0.08)$ & 0.26 \\
\hline $50-59$ years & $2.98 \%(2.83-3.13)$ & $1.92 \%(1.82-2.03)$ & $1.66 \%(1.57-1.75)$ & $1.38 \%(1.31-1.46)$ & $<0.0001$ \\
\hline $60-69$ years & $13.20 \%(12.86-13.55)$ & $8.39 \%(8.12-8.67)$ & $7.27 \%(7.03-7.51)$ & $6.01 \%(5.82-6.20)$ & $<0.0001$ \\
\hline $70-79$ years & $24.79 \%(24.19-25.40)$ & $16.66 \%(16.20-17.12)$ & $14.45 \%(14.05-14.87)$ & $11.44 \%(11.09-11.79)$ & $<0.0001$ \\
\hline$>80$ years & $28.59 \%(27.53-29.67)$ & $18.14 \%(17.36-18.95)$ & $14.57 \%(13.96-15.19)$ & $12.28 \%(11.78-12.79)$ & $<0.0001$ \\
\hline \multicolumn{6}{|c|}{ Five-year cumulative incidence of BPO surgery } \\
\hline$<50$ years & $0.26 \%(0.24-0.28)$ & $0.22 \%(0.20-0.24)$ & $0.21 \%(0.19-0.23)$ & $0.24 \%(0.22-0.26)$ & 0.08 \\
\hline $50-59$ years & $8.48 \%(8.23-8.73)$ & $6.03 \%(5.84-6.22)$ & $5.28 \%(51.12-5.44)$ & $4.64 \%(4.50-4.78)$ & $<0.0001$ \\
\hline $60-69$ years & $31.03 \%(30.50-31.56)$ & $22.53 \%(22.09-22.97)$ & $19.19 \%(18.80-19.58)$ & $16.93 \%(16.61-17.25)$ & $<0.0001$ \\
\hline $70-79$ years & $53.25 \%(52.37-54.15)$ & $38.16 \%(37.47-38.86)$ & $33.27 \%(32.65-33.90)$ & $28.51 \%(27.96-29.07)$ & $<0.0001$ \\
\hline$>80$ years & $51.05 \%(49.63-52.49)$ & $34.87 \%(33.78-35.98)$ & $28.37 \%(27.53-29.24)$ & $25.69 \%(24.96-26.43)$ & $<0.0001$ \\
\hline
\end{tabular}

BPO: benign prostatic obstruction. 


\begin{tabular}{|c|c|c|c|c|c|c|c|c|c|}
\hline & \multicolumn{4}{|c|}{ Prior to 2002} & \multicolumn{4}{|c|}{ After 2002} & \multirow{2}{*}{$\begin{array}{c}\text { Difference in change per } \\
\text { year (pre-2002 vs. } \\
\text { post-2002) (p) }\end{array}$} \\
\hline & $\begin{array}{l}\text { Start } \\
\text { of } \\
\text { period }\end{array}$ & $\begin{array}{l}\text { End of } \\
\text { period }\end{array}$ & $\begin{array}{l}\text { Change } \\
\text { per year }\end{array}$ & $\mathbf{p}$ & $\begin{array}{c}\text { Start } \\
\text { of } \\
\text { period }\end{array}$ & $\begin{array}{l}\text { End of } \\
\text { period }\end{array}$ & $\begin{array}{l}\text { Change } \\
\text { per year }\end{array}$ & $\mathbf{p}$ & \\
\hline TURP & $97.18 \%$ & $96.98 \%$ & 0.16 & 0.67 & $92.05 \%$ & $76.93 \%$ & -1.41 & 0.027 & 0.003 \\
\hline $\begin{array}{l}\text { Endoscopic laser } \\
\text { prostatectomy }\end{array}$ & $0 \%$ & $0 \%$ & -0.10 & 0.71 & $3.45 \%$ & $21.94 \%$ & 1.67 & 0.0008 & $<0.0001$ \\
\hline $\begin{array}{l}\text { Open/lap } \\
\text { prostatectomy }\end{array}$ & $1.52 \%$ & $1.36 \%$ & 0.03 & 0.62 & $2.55 \%$ & $0.98 \%$ & -0.13 & 0.07 & 0.008 \\
\hline Other & $1.30 \%$ & $1.66 \%$ & -0.05 & 0.51 & $1.96 \%$ & $0.16 \%$ & -0.10 & 0.37 & 0.53 \\
\hline
\end{tabular}

BPO: benign prostatic obstruction; TURP: transurethral resection of the prostate

\begin{tabular}{|c|c|c|c|c|c|c|c|c|c|}
\hline \multicolumn{10}{|c|}{ Supplementary Table 1. Trends in the use of surgical interventions for BPO from 1994-2014, stratified by age group. } \\
\hline & \multicolumn{4}{|c|}{ Prior to 2002} & \multicolumn{4}{|c|}{ After 2002} & \multirow{2}{*}{$\begin{array}{l}\text { Difference in change per } \\
\text { year (pre-2002 vs. } \\
\text { post-2002) (p) }\end{array}$} \\
\hline & $\begin{array}{c}\text { Start } \\
\text { of } \\
\text { period* }\end{array}$ & $\begin{array}{l}\text { End of } \\
\text { period }^{*}\end{array}$ & $\begin{array}{c}\text { Change } \\
\text { per } \\
\text { year }\end{array}$ & $\mathbf{p}$ & $\begin{array}{c}\text { Start } \\
\text { of } \\
\text { period* }\end{array}$ & $\begin{array}{l}\text { End of } \\
\text { period }\end{array}$ & $\begin{array}{l}\text { Change } \\
\text { per year }\end{array}$ & $\mathbf{p}$ & \\
\hline$<50$ years & 0.18 & 0.20 & -0.003 & 0.15 & 0.15 & 0.16 & 0.002 & 0.47 & 0.025 \\
\hline $50-59$ years & 2.34 & 1.36 & -0.141 & $<0.0001$ & 1.26 & 0.92 & -0.023 & 0.36 & $<0.0001$ \\
\hline $60-69$ years & 7.10 & 3.98 & -0.470 & $<0.0001$ & 3.83 & 2.89 & -0.081 & 0.17 & $<0.0001$ \\
\hline $70-79$ years & 9.69 & 5.85 & -0.612 & $<0.0001$ & 5.29 & 3.91 & -0.144 & 0.009 & $<0.0001$ \\
\hline$\geq 80$ years & 4.42 & 2.43 & -0.294 & $<0.0001$ & 2.38 & 1.71 & -0.056 & 0.045 & $<0.0001$ \\
\hline
\end{tabular}

*Age-standardized rate of BPO procedures per 10000 population. BPO: benign prostatic obstruction. 


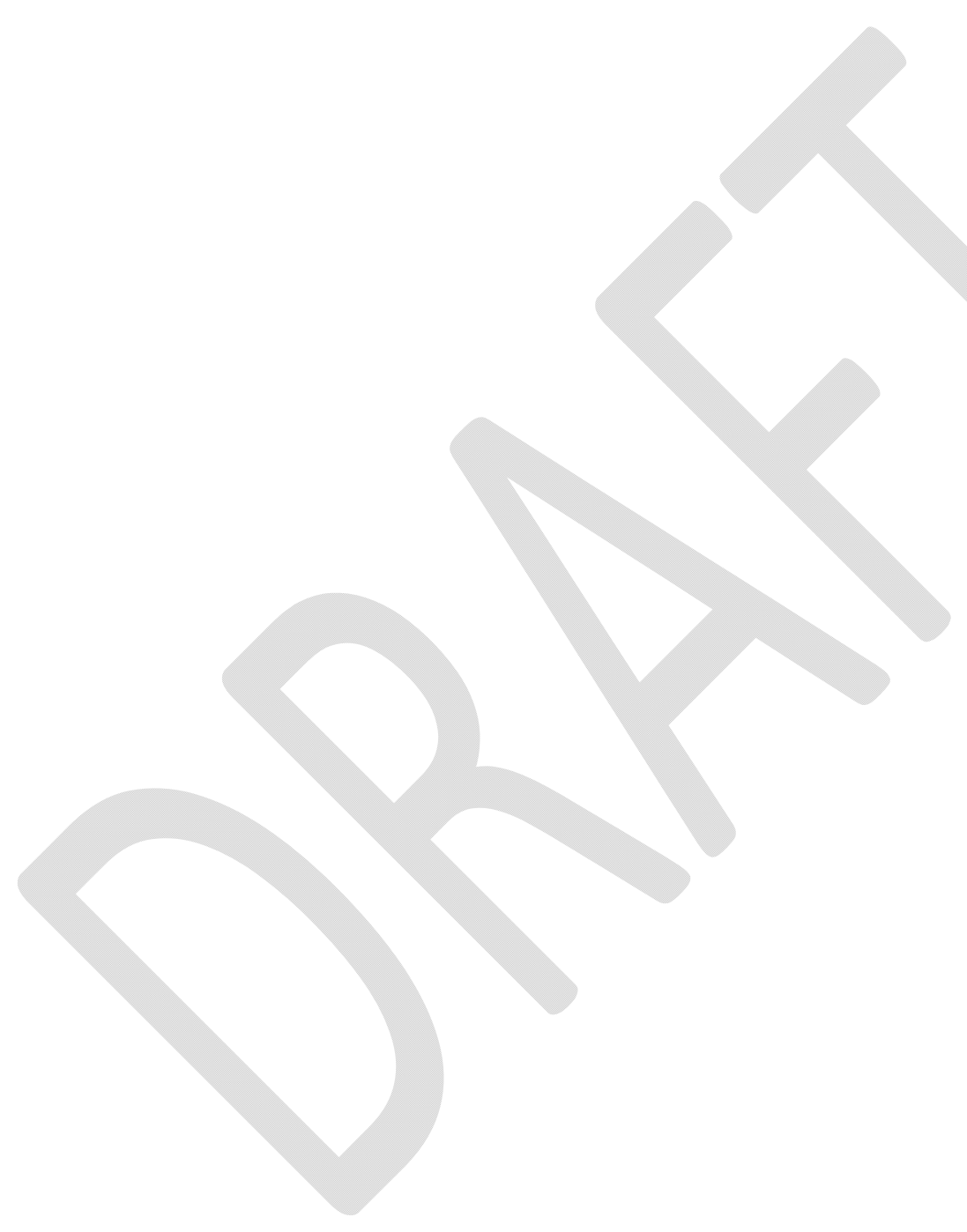

